\title{
NUTRITIVE EVALUATION AND PHYTOCHEMICAL COMPOSITION OF UNDERUTILIZED INDIGENOUS EDIBLE FRUITS OF VELLIANGIRI HILLS, COIMBATORE DISTRICT
}

\author{
Aghil Soorya, A*., K. Thenmozhi, K. Karthika, S. Jamuna and S. Paulsamy \\ PG and Research Department of Botany, Kongunadu Arts and Science College, Coimbatore - 641029. \\ *E.mail: aghilsoorya@gmail.com
}

\begin{abstract}
The study was aimed to explore the nutritional status of 5 indigenous edible fruits viz., Ziziphus jujuba, Limonia acidissima, Ziziphus oenoplia, Phyllanthus emblica and Ficus racemosa along with their phytochemical profile. Phosphorous content was determined using indophenol blue method; $\mathrm{K}, \mathrm{Ca}, \mathrm{Mg}, \mathrm{Fe}$ and $\mathrm{Zn}$ contents were determined using atomic absorption spectrophotometer. Qualitative and quantitative estimations were carried out using standard procedures. In the present study, all the investigated samples presented substantial amount of $\mathrm{P}, \mathrm{Ca}, \mathrm{Mg}, \mathrm{Fe}$ and $\mathrm{Zn}$ content. The qualitative analysis revealed the presence alkaloids, phenols and flavonoids in all the five investigated samples. However, tannins were detected only in Limonia acidissima and Ficus recemosa; whereas steroids were absent in Limonia acidissima and Phyllanthus emblica. The quantitative analysis also exhibited appreciable amount of phenolic (47 to $85 \mathrm{mg} \mathrm{GAE} / \mathrm{g}$ sample) and flavonoid contents (12 to $61 \mathrm{mg} \mathrm{RE} / \mathrm{g}$ sample). Thus the study confirmes that wild edible fruits investigated are a promising source of essential nutrients such as $\mathrm{P}, \mathrm{K}, \mathrm{Ca}, \mathrm{Zn}, \mathrm{Mg}$ and Fe. Phytochemical study also confirmed the presence of the adequate quantities of secondary metabolites of medicinal importance thus exemplifies therapeutic values.
\end{abstract}

Keywords: Edible fruits, nutritive evaluation, phytochemcial contents.

\section{INTRODUCTION}

Plants have been of great importance due to their nutritive value and continue to be a major source of medicine. 30 to $40 \%$ of today's conventional drugs employed in herbal supplements as botanicals, nutraceuticals, drugs are emerged from the curative properties of various plant species. Caloric requirements to meet the demand are also comparatively high. Therefore, plant materials form a major portion of the diet and so evaluation of their nutritive value is very important.

Many wild fruits notably Amla, Harida, Bel, Elephant apple have been exploited from wild for centuries across Indian subcontinent on account of its food and medicinal properties. The therapeutic efficacy of many indigenous plants for various diseases has been described by traditional herbal medicinal practitioners. Some wild plants have been identified to have better nutritional value than the cultivated ones. As a result, in recent years, a growing interest has been emerged to evaluate various wild edible plants for their nutritional features. The medicinal importance of fruit is due to the presence of some bioactive components such as alkaloids, glycosides, resins, volatile oils, gums, tannins, etc.
The wild edible species are gathered mostly for home consumption mainly by forest dwellers, tribal and marginalized rural communities. But information on edibility and therapeutic properties of wild fruits is scanty and data on their nutritional composition is also negligible. Therefore, the present study was adressed to explores the nutritional status of five indigenous edible fruits viz., Ziziphus jujuba, Limonia acidissima, Ziziphus oenoplia, Phyllanthus emblica and Ficus racemosa along with their phytochemical profiles such as phenolics, tannins and flavonoids.

\section{MATERIALS AND METHODS}

\subsection{Sample collection and preparation}

Wild edible fruits of Ziziphus jujuba, Limonia acidissima, Ziziphus oenoplia, Phyllanthus emblica and Ficus racemosa were collected during the month of November- December, 2014 from Velliangiri hills, Poondi, Coimbatore. The authenticity of the selected plant species were confirmed by comparing with the reference specimens preserved at Botanical Survey of India, Southern Circle, Coimbatore. The fruits from respective species were cleaned, washed with copious amount of distilled water, shade dried, chopped into bits, and coarsely powdered in a Willy mill to 60 mesh. 


\subsection{Preparation of crude plant extracts}

$50 \mathrm{~g}$ of coarsely powdered plant samples were subjected to ethanol $(\mathrm{w} / \mathrm{v})$ extraction at a controlled temperature using soxhlet apparatus. The extracts were concentrated to dryness under reduced pressure using rotary vacuum evaporator (supervac R-185, India), lyophilized to remove traces of water molecules and were stored at $-20^{\circ} \mathrm{C}$ for further studies.

\subsection{Sample analysis}

Phosphorus(P) was determined by Indophenol blue method; while, Potassium (K), Calcium (Ca), Magnesium (Mg), Iron (Fe) and Zinc (Zn) contents were determined using atomic absorption spectrophotometer (Biricik and Baroglu, 2006; Kazankaya et al., 2008).

\subsection{Qualitative analysis of the extracts}

The concentrated extracts were subjected to qualitative tests for the identification of various phytochemical constituents viz., alkaloids, phenols, flavonoids, tannins and steroids as per standard procedures (Harborne, 1984; Trease and Evans, 1989; Sofowora, 1993).

\subsection{Quantification of non-enzymic antioxidants}

\subsubsection{Total phenolics and tannins}

The total phenolic content of the plant extracts were determined using Folin-Ciocalteu reagent according to the method described by Siddhuraju and Becker (2003). In this method, $20 \mu \mathrm{g}$ of the extract (dissolved in the respective solvent) was taken in a test tube and made upto the volume of $1.0 \mathrm{ml}$ with distilled water. Then $0.5 \mathrm{ml}$ of freshly prepared Folin-Ciocalteu phenol reagent (1:1) with water and $2.5 \mathrm{ml}$ of $20 \%$ sodium carbonate solution were added sequentially in each tube. The mixtures were agitated and left in dark at laboratory temperature for $40 \mathrm{~min}$ for the development of colour. The absorbance was recorded at $725 \mathrm{~nm}$ against the reagent blank using spectrophotometer (Shimadzu-UV-160 Japan). A calibration curve of gallic acid was constructed, and linearity was observed in the range of $10-50 \mu \mathrm{g} / \mathrm{ml}$. Using the standard curve, the total phenol content of the extract was calculated and expressed as Gallic Acid Equivalents (GAE $\mathrm{mg} / \mathrm{g}$ extract). Using the same extract, tannin content was estimated after treatment with polyvinyl polypyrrolidone (PVPP) as described by Siddhuraju and Manian (2007). 100mg of PVPP was weighed in a 100x12 mm test tube and to this, $1 \mathrm{ml}$ distilled water and $1 \mathrm{ml}$ of tannin containing phenolic extract was added. The contents were vortexed and kept at $4^{\circ} \mathrm{C}$ for 15 mins. Then the sample was centrifuged (5000rpm for $10 \mathrm{mins}$ at laboratory temperature) and the supernatant was collected. This supernatant has only simple phenolics other than tannins (the tannins would have been precipitated along with the PVPP). The phenolic content of the supernatant was measured as monitored above and expressed as the content of free phenolics on a dry matter basis. From the above results, the tannin content of the extract was calculated as follows:

Tannin $=$ Total phenolic - Free phenolics

\subsubsection{Total flavonoid content}

The total flavonoid content was determined spectrophotometrically using the method adopted by Zhishen et al.(1999). $0.5 \mathrm{ml}$ of appropriately diluted extract solution was mixed with $2 \mathrm{ml}$ of distilled water and subsequently with $0.15 \mathrm{ml}$ of $5 \%$ sodium nitrate solution and maintained for $6 \mathrm{mins}$. Then,

$0.15 \mathrm{ml}$ of $10 \%$ aluminium chloride solution was added and allowed to stand for $6 \mathrm{mins}$, and finally 2 $\mathrm{ml}$ of $4 \%$ sodium hydroxide solution was added. Final volume of the content was made upto $5 \mathrm{ml}$ with distilled water and were mixed thoroughly. After 15 mins of incubation at laboratory temperature, the absorbance was determined against blank at $510 \mathrm{~nm}$. The total flavonoid content was determined using a standard curve with rutin. The mean of the three values were expressed as milligrams of rutin equivalents (mg RE/g extract) on a dry weight basis.

\section{RESULTS}

The elemental mineral contents of five different wild edible fruits such as Ziziphus jujuba, Limonia acidissima, Ziziphus oenoplia, Phyllanthus emblica and Ficus racemosa were attempted and depicted in Table 1. Results revealed that Potassium $(\mathrm{K})$, Iron $(\mathrm{Fe})$, Calcium (Ca), Magnesium (Mg), Phosphorus (P) and Zinc (Zn) contents varied widely between plant samples analyzed. In the present study, potassium content ranged between 0.012 and $0.278 \mathrm{mg} / \mathrm{g}$ dried sample. However, among the samples investigated, Ficus racemosa $(0.278 \mathrm{mg} / \mathrm{g})$ fruit registered high levels of potassium content followed by Limonia acidissima fruit $(0.185 \mathrm{mg} / \mathrm{g})$; on the other hand, Ziziphus jujuba fruit $(0.012 \mathrm{mg} / \mathrm{g})$ recorded very low content of potassium (Table 1 ).

Concentration of calcium in various wild edible fruit samples were analysed and presented in Table 1. It was in the range of 0.096 and $0.176 \mathrm{mg} / \mathrm{g}$. Phyllanthus emblica $(0.0176 \mathrm{mg} / \mathrm{g})$ fruit contained 
the highest levels of calcium content followed by Ziziphus jujuba $(0.151 \mathrm{mg} / \mathrm{g})$ and Ficus racemosa $(0.119 \mathrm{mg} / \mathrm{g})$ fruit; whereas Limonia acidissima fruit $(0.096 \mathrm{mg} / \mathrm{g})$ displayed very low content of calcium. Similarly in all the wild edible fruits tested, Ziziphus oenoplia fruit $(0.192 \mathrm{mg} / \mathrm{g})$ displayed relatively higher amount of magnesium followed by Phyllanthus emblica fruit $(0.154 \mathrm{mg} / \mathrm{g})$; while Ficus racemosa fruit $(0.09 \mathrm{mg} / \mathrm{g})$ and Ziziphus jujuba fruit $(0.039 \mathrm{mg} / \mathrm{g})$ broadly arrayed very low values.

The iron content of 5 different wild edible fruit samples viz., Ziziphus jujuba, Limonia acidissima,

Table 1. Proximate composition of wild edible fruits
Ziziphus oenoplia, Phyllanthus emblica and Ficus racemosa were examined and their results were presented in Table 1. Obviously, it was observed that all the samples investigated displayed remarkably appreciable amount of their contents (Table 1). Additionally, Ziziphus jujuba $(7.11 \mathrm{mg} / \mathrm{g})$ followed by Phyllanthus emblica (4.26 mg/g) and Ficus racemosa $(2.68 \mathrm{mg} / \mathrm{g}$ ) fruits were found to have markedly higher amount of their contents than that of the other said samples investigated.

\begin{tabular}{|c|c|c|c|c|c|c|c|}
\hline S.No. & Sample & $\begin{array}{c}\text { Potassium } \\
\text { (K) } \\
\mathrm{mg} / \mathrm{g}\end{array}$ & $\begin{array}{c}\text { Calcium } \\
\text { (Ca) } \\
\mathrm{mg} / \mathrm{g}\end{array}$ & $\begin{array}{c}\text { Magnesium } \\
\text { (Mg), } \\
\mathrm{mg} / \mathrm{g}\end{array}$ & $\begin{array}{l}\text { Iron } \\
\text { (Fe) } \\
\mathrm{mg} / \mathrm{g}\end{array}$ & $\begin{array}{l}\text { Zinc } \\
\text { (Zn) } \\
\mathrm{mg} / \mathrm{g}\end{array}$ & $\begin{array}{c}\text { Phosphorus } \\
\text { (P) } \\
\mathrm{mg} / \mathrm{g}\end{array}$ \\
\hline 1 & Ziziphus jujuba & 0.012 & 0.151 & 0.039 & 7.11 & 0.105 & 0.049 \\
\hline 2 & $\begin{array}{l}\text { Limonia } \\
\text { acidissima }\end{array}$ & 0.185 & 0.096 & 0.147 & 0.32 & 0.072 & 0.054 \\
\hline 3 & $\begin{array}{l}\text { Ziziphus } \\
\text { oenoplia }\end{array}$ & 0.023 & 0.103 & 0.192 & 0.823 & 0.067 & 0.025 \\
\hline 4 & $\begin{array}{l}\text { Phyllanthus } \\
\text { emblica }\end{array}$ & 0.104 & 0.176 & 0.154 & 4.26 & 0.056 & 0.019 \\
\hline 5 & Ficus racemosa & 0.278 & 0.119 & 0.090 & 2.68 & 0.126 & 0.095 \\
\hline
\end{tabular}

Table 2. Qualitative phytochemical analysis of wild edible fruits.

\begin{tabular}{cccccccc}
\hline \multirow{2}{*}{ S.No. } & \multirow{2}{*}{ Sample } & \multicolumn{5}{c}{ Secondary metabolites } \\
\cline { 2 - 7 } & Alkaloids & Tannins & Phenols & Flavonoids & Steroids & Terpenoids \\
\hline 1 & Ziziphus jujuba & +++ & - & +++ & +++ & + & + \\
2 & Limonia acidissima & +++ & + & +++ & ++ & - & +++ \\
3 & Ziziphus oenoplia & ++ & - & ++ & - & + & ++ \\
4 & Phyllanthus emblica & +++ & - & +++ & ++ & - & ++ \\
5 & Ficus racemosa & +++ & + & ++ & +++ & ++ & ++ \\
\hline
\end{tabular}

+++ indicate high degree of presence, ++ indicate moderate degree of presence, + indicate low degree of presence and Indicate the absence.

Table 3. Phenolic, tannins and total flavonoid contents of wild edible fruits.

\begin{tabular}{clccc}
\hline S.No. & \multicolumn{1}{c}{ Sample } & $\begin{array}{c}\text { Total phenolics (mg } \\
\text { GAE/g sample) }\end{array}$ & $\begin{array}{c}\text { Tannins (mg GAE/g } \\
\text { sample) }\end{array}$ & $\begin{array}{c}\text { Total Flavonoids } \\
\text { (mg RE/g sample) }\end{array}$ \\
\hline 1 & Ziziphus jujuba & 47 & 15 & 41 \\
2 & Limonia acidissima & 52 & 19 & 61 \\
3 & Ziziphus oenoplia & 65 & 16 & 45 \\
4 & Phyllanthus emblica & 72 & 19 & 33 \\
5 & Ficus racemosa & 85 & 32 & 12 \\
\hline
\end{tabular}

GAE - Gallic Acid Equivalents; RE - Rutin Equivalents

In the present study, the zinc content for the 5 different wild edible fruits were determined and presented in Table 1. However among the samples analyzed, Ficus racemosa $(0.126 \mathrm{mg} / \mathrm{g})$ and Ziziphus jujuba $(0.015 \mathrm{mg} / \mathrm{g})$ fruits unveiled higher contents. On the other hand, Phyllanthus emblica $(0.056 \mathrm{mg} / \mathrm{g})$ fruit displayed very low content of Zinc. Similarly among the samples examined, Ficus racemosa 0.095 $\mathrm{mg} / \mathrm{g}$ ) exhibited substantial amount of phosphorous content followed by Limonia acidissima $(0.054 \mathrm{mg} / \mathrm{g})$ fruit. In contrast, Phyllanthus emblica $(0.019 \mathrm{mg} / \mathrm{g})$ fruit determined significantly very low content of Phosphorus (Table 1). 


\subsection{Preliminary qualitative phytochemical analysis}

In the present study, the presence of various secondary metabolites such as alkaloids, tannins, flavonoids, phenols, steroids and terpenoids in wild edible fruits of Ziziphus jujuba, Limonia acidissima, Ziziphus oenoplia, Phyllanthus emblica and Ficus racemosa were attempted and presented in Table 2 . The study revealed that among the samples examined, Ziziphus jujuba, Limonia acidissima, Ziziphus oenoplia, Phyllanthus emblica and Ficus racemosa fruit registered the presence of a variety of secondary metabolites such as phenols, alkaloids, flavonoids and terpenoids with high degree of prevalence (Table 2). While comparatively very low levels of tannins were detected in Limonia acidissima and Ficus racemosa; whereas in case of Ziziphus jujuba, Ziziphus oenoplia and Phyllanthus emblica fruit, tannins were not detected. On the other hand, steroids were present only in trace amount in the investigated samples (Table 2) and it was absent in Limonia acidissima and Phyllanthus emblica fruit.

\subsection{Quantification of Phenolics, Tannins and Flavonoids}

Using Folin-Ciocalteu's reagent, amount of total phenolic constituents for the wild edible fruits viz., Ziziphus jujuba, Limonia acidissima, Ziziphus oenoplia, Phyllanthus emblica and Ficus racemosa were estimated and presented in Table 3. The amount of total phenolic and tannin contents were varied widely between $47 \mathrm{mg} \mathrm{GAE} / \mathrm{g}$ and $85 \mathrm{mg}$ GAE/g sample, respectively. In particular, Ficus racemosa (85 mg GAE/g sample) and Phyllanthus emblica (72 mg GAE/g samples) fruits exhibited appreciable amount of polyphenolic contents. Similarly, the total phenolic content varied considerably between $12 \mathrm{mg}$ GAE/g and $61 \mathrm{mg}$ $\mathrm{GAE} / \mathrm{g}$ of dried samples. Among the investigated samples, Limonia acidissima registered high flavonoid contents(61 mg RE/g of dried sample) followed by Ziziphus oenoplia fruit (45mg RE/g of dried sample). Whereas, Ficus racemosa fruit (12 mg $\mathrm{RE} / \mathrm{g}$ of dried sample), registered minimal levels of total flavonoid contents being detected under the experimental conditions tested.

\section{DISCUSSION}

Wild edible fruits offer tremendous application as they can be used as food and medicines besides their key ecological roles. It represents one of the world's greatest untapped resources of nutrition and palatable food of the future. They generally possess most of the attributes of nutritious food as they contain many essential nutrients and antioxidants in good quantity. Therefore proximate and nutrient analysis of wild edible fruits play a crucial role in assessing their nutritional significance. As various medicinal plant species are also used as food along with their medicinal benefits, evaluating their nutritional significance can help to understand the worth of these plant resources.

Despite such claims, in the present investigation, an attempt has been made to explore underutilized indigenous edible fruits of Velliangiri hills for their nutritive and phytochemical evaluation. In the present study, the average values of the nutritive elements present in various edible fruits were presented in Table 1 . The results of the nutritional profile of wild edible fruits viz., Ziziphus jujuba, Limonia acidissima, Ziziphus oenoplia, Phyllanthus emblica and Ficus racemosa revealed that all the samples investigated determined high calories of nutritive value (Table 1) and thus are considered as an excellent source for human consumption.

In elemental compositional analysis, among the samples investigated, Ficus racemosa fruit is considered as a good source of nutrition as they possess high content of $\mathrm{K}, \mathrm{Zn}$ and $\mathrm{P}$ (Table 1). Similarly, the fruits of Ziziphus jujuba and Ziziphus oenoplia also registered high content of Fe and Mg.

Anandakumar et al. (2009) reported that the presence of secondary metabolites like alkaloids, phenols, flavonoids, steroids, glycosides and saponins in plants is the basic character for their medicinal properties. The species with high content of alkaloids and flavonoids generally indicate that they are medicinally important for the treatment of diuretic, antispasmodic, antiseptic and antidote actions (Jeeshna et al., 2010). High phenolic content generally have antibacterial and antiviral activities. Flavonoids, on the other hand are potent watersoluble antioxidant and free radical scavengers which prevent oxidative cell damage and have strong anticancer activity (Paulsamy and Jeeshna, 2011). Considering the above facts, the presence of all these compounds in the investigated sampes (Table 2), thus justifies its medicinal claims. The difference in chemical contents of fruits observed in this study could be due to genetic differences (Beyhan et al., 2011).

Phenolic compounds are an important group of secondary metabolites, which are synthesized by plants for protection against predators. In the present study, the contents of total 
phenolics and tannin contents varied widely between $47 \mathrm{mg} \mathrm{GAE} / \mathrm{g}$ and $85 \mathrm{mg}$ GAE/g sample; 15 $\mathrm{mg}$ GAE/g and $32 \mathrm{mg}$ GAE/g respectively. The observed variation might be due to the marked difference in the qualitative and quantitative composition of phenolic compounds and their conjugates present in these extracts. However among the samples investigated, Ficus racemosa fruit registered substantial amount of active compounds which might offer a good source of nutritional antioxidant defence against reactive oxygen species involved in the initiation of deleterious free radical reaction (Thenmozhi et al., 2012).

Flavonoids, the most wide spread group of natural compounds occur naturally in a wide range of plant species. They are phenolic derivative present in substantial amount in plants. In the present study, the total flavonoid content varied considerably between $12 \mathrm{mgRE} / \mathrm{g}$ and $61 \mathrm{mgRE} / \mathrm{g}$ of dried sample. Food derived flavonoids, especially flavonols (kaempferol and quercetin) are widely occurring flavonoids are known to possess multiple biological functions such as antioxidant, antiartherogenic, antiallergic, cardioprotecive and vasodialatory effects (Thenmozhi et al., 2012).

\section{CONCLUSION}

Based on the active profile exposed, Ziziphus jujuba, Limonia acidissima, Ziziphus oenoplia, Phyllanthus emblica and Ficus racemosa have revealed that these plants are a good source of nutrients and can be used as a substrates deficient in either of these nutrients. The study also confirmed the therapeutic value and furthermore its folklore medicinal value in the presence of adequate amount of secondary metabolites such as phenolics, tannins, sterols, flavonoids and terpenoids. The present investigation has opened up a new arena of using this wild edible fruits with nutraceutical perspective in the field of drug development. Therefore, assessment of antioxidant properties might be a fruitful approach for advocating them in the field of nutraceuticals and therapy.

\section{REFERENCES}

Beyhan, 0., M.A. Bozkurt and S.C. Boysal, (2011). Determination of macro-micro nutrient content in dried fruit and leaves and some pomological characteristics of selected Feijoa Genotypes (Feijoa swllowiana Berg.) from Sakarya Provinces in Turkey. The J. Animal Plant Sci. 21(2): 251-155.
Biricik, G. F. and F. Basoglu, (2006). Determination of mineral contents in some olives (Samanli, Domat, Manzanilla, Ascolana) varieties. Gida, 31(2):67-75.

Harborne, J.B. (1984). Phytochemical Methods; A guide to modern techniques of plant Analysis. $2^{\text {nd }}$ Edition, London, New York.

Jeeshna, M.V. and S. Paulsamy, (2011). Evaluation of Certain flavonoids of medicinal importance in the wild and micropropogated plants of the endangered medicinal species, Exacum bicolor Roxb. J. Appl. Pharmaceu. Sci. 01(05): 99-102.

Jeeshna, M.V., T. Mallikadevi And S. Paulsamy, (2010). Screening of the weed plant species, Croton bonplandianum Baill. for larvicidal activity of Aedes aegypti. J. Biopesticid. 3(1): 192-194.

Kazankaya, A., F. Balta, N. Ozturk and F. Sonmez, (2008). Mineral composition of Pistacia (Pistacia vera L.) from Siirt Turkey. Asian J. Chem. 20(3): 2337-2343.

Siddhuraju, P. And S. Manian, (2007). The antioxidant activity and free radical scavenging capacity of dietary phenolic extracts from horse gram (Macrotyloma uniflorum (Lam.) Verdc.) seeds. Food Chem. 105, 950-958 (Elsevier, UK).

Siddhuraju. P and K. Becker, (2003). Antioxidant properties of various solvent extracts of total phenolic constituents from three different agroclimatic origins of drumstick tree (Moringa oleifere Lam.) leaves. J. Agric. Food Chem. 51: 2144-2155.

Sofowora, A. (1993). Medicinal Plants and Traditional Medicinal in Africa. $2^{\text {nd }}$ Ed. Sunshine House, Ibadan, Nigeria: Spectrum Books Ltd;. Screening Plants for Bioactive Agents, p. 134156.

Thenmozhi, K., D. Praveenkumar, E. Priya, A. Nagasathy, N. Thajuddin, (2012). Evaluation of aromatic and polycyclic hydrocarbon degrading abilities of selected bacterial isolates. J. Microbiol. Biotech. Res. 2(3): 445-449.

Trease, G.E. and W.C. Evans, (1989). Pharmacology. $11^{\text {th }}$ Edn., Bailliere Tindall Ltd., London, p. 6075.

Zhishen, J, Mengcheng, T and W. Jianming, (1999). The determination of flavonoid contents in mulberry and their scavenging effects on superoxide radicals. Food Chem. 64: 555-559. 